\title{
Failure to Attract and Retain Clinician/Scientist Faculty Puts Our Profession at Risk
}

\author{
Paul H. Krebsbach and Michael A. Ignelzi, Jr. \\ University of Michigan School of Dentistry, Ann Arbor, Michigan
}

$\mathrm{T}$ The 77th General Session of the IADR, held last March in Vancouver, Canada, enjoyed the third largest attendance ever and was a success on many levels. This meeting, historically an important showcase for student research, also brought to light a conspicuous shortcoming: Despite the large number of students actively involved in research during dental school, very few go on to pursue careers as clinician/scientists.

The NIDCR, the Institutional Dentist Scientist Award program, and other training grant directors are keenly aware of the need for new recruitment and retention strategies. In response to these concerns, NIDCR leaders convened a symposium, "Attracting Students to Oral Health Research", in Vancouver to define the problems and discuss strategies for developing solutions. Several past and present students described perceived obstacles and threats to a scientific career. More importantly, the discussion turned to experiences that inspired some students to pursue careers in the oral health sciences.

Superb mentoring from encouraging role models emerged as a key element in choosing a career in academic dentistry. If mentoring is essential to nurturing students' scientific curiosity, we must provide it. A major problem, however, is that many faculty members are being asked to do more in already-demanding assignments. Faculty are expected to become "triple threats", excelling in teaching, patient care, and funded research.

Although these are the very challenges that attracted many of us to academic careers, it is often difficult to share our passion for discovery with all students. A few fortunate ones get the chance to work closely with faculty members in summer research programs, but most students see only the time requirements, energy demands, and frustration levels of busy faculty members, many of whom could be earning more as practitioners.

\section{An educational environment for expanding ideas}

Our current approach to dental education impedes our ability to recruit dental students into academic careers, perhaps because our approach of training dentists has become too narrow. First-year dental students come from a diverse range of backgrounds, interests, and academic achievements. Our collective mindset and curricula are focused on producing general dentists or specialists, but do not provide an environment to nurture future academicians.

It may seem obvious that the job of the dental faculty is to train dentists, but we also need to create an environment for the expansion of ideas. Rather than defining graduation from dental school as the endpoint to a career in dentistry, we should be open to the idea that graduation can be a springboard into equally rewarding, non-traditional careers. Dental school graduates can pursue non-traditional opportunities as clinician/scientists, investigators, or executives in the health care or pharmaceutical industries. They may become science writers, attorneys, or policymakers in government, health care, or insurance industries.

Because creativity is an essential part of the nature of researchers, faculty members need to work harder and smarter to create an environment that nurtures the creative nature of our students. One way we can work smarter is to improve communication between primary clinical faculty and our colleagues in basic science. Their mutual failure to understand and appreciate each other's role in dental education limits the perceptions of our students. It's not difficult to imagine the negative impression conveyed by a clinical instructor who tells students, "Clinical knowledge is what you really need to be a dentist" or "Basic science research is a waste of time". Likewise, basic science researchers who lecture extensively on their narrow topic of interest without making clinical correlations can discourage a student from science.

As some dental schools increase clinical exposure at the expense of basic science, faculty members need to communicate the balance between the clinical art of our profession and its foundation in basic science. By our example, our students will learn to appreciate the value of basic science.

\section{The challenges of retaining research talent}

To ensure a vibrant profession in the years to come, we must retain the people who choose to pursue careers as clinician/scientists. First, we must train these people so that 
they are well-equipped to compete for extramural funds. And second, we must create a nurturing environment to support these people in their early years as faculty. Researchers who seek extramural funding must be armed with a doctoral dissertation and a robust post-doctoral experience. Although some researchers have become successful without post-doctoral experience, we live in an era where two, and sometimes three, separate and distinct postdoctoral fellowships are becoming the norm. For most people, attempting to engage in competitive science without a "post-doc" is a recipe for disaster. The post-doctoral fellowship is critical because it allows students to mature scientifically, expand their repertoire of experimental approaches, and broaden their network of colleagues and mentors. Most, if not all, reviewers in study sections have completed some post-doctoral experience, and they may be skeptical of applicants who lack similar advanced training.

Once the post-doctoral fellowship is complete and the first faculty position begins, it is crucial to create a nurturing environment that fosters early success. A competitive salary, laboratory space, and protected time are certainly important, but for most clinician/scientists the most important element for success is a stimulating intellectual environment. Mentors, colleagues, and students all contribute to the intellectual growth of new faculty members. Given the rapid pace of advances in the life sciences, a scientist who fails to grow intellectually will not be competitive for very long.

\section{Strategies to attract and retain clinician/scientific faculty}

The following suggestions for attracting and retaining the oral health science leaders of tomorrow represent the ideas of several colleagues and the results of many discussions. They are starting points, designed to kindle the fire of debate and motivate our leaders to action.

(1) Break the mold for a small percentage of incoming firstyear students. By modifying the admissions criteria for a percentage of the freshman class, dental schools could admit students who can handle the academic challenge but may not fit the typical first-year student profile. These students may be from unusual backgrounds, think differently, or be creative in ways not always associated with high test scores. They could become general dentists like the majority of the class, or they might just become the next generation of leaders in academic dentistry.

(2) Give credit for scientific pursuits. Students should receive credit toward a dental degree for scientific activities such as presenting an abstract at a research meeting. This would not relieve students of the requirements of maintaining clinical proficiency, but this credit may give students the impetus and freedom to be creative and to pursue individual interests.

(3) Establish scholarships for non-traditional studies. Dental schools should establish annual scholarships to allow students to pursue professional enhancement activities. Only imagination limits the creative journeys that a one-year sabbatical might take. Serving as a research fellow in a world-class laboratory, as a Congressional science fellow on Capitol Hill for a US Senator working on public health issues, interning as a science writer for the New York Times are only a few of the experiences that would greatly enrich the professional lives of promising young academicians.

(4) Develop exchange programs for summer research students. The successful NIDCR intramural program offers a stipend for a summer research experience at the National Institutes of Health. Expanding this program between dental schools with summer research programs would broaden both the research and life experiences of visiting students.

(5) Increase interaction between regional dental schools. Although many schools have organized student research groups, dental schools within a reasonable geographic distance should pool resources to celebrate their research activities at regional annual symposia. Such events would expand students' exposure to ideas and opportunities beyond the walls of their own schools. Shared experiences of successes, obstacles, and opportunities would stimulate the interest of students considering a career in oral health sciences.

(6) Promote mentoring. Mentoring is critical at all levels. Good advice is invaluable whether you are beginning a career, serving on study section for the first time, or considering a sabbatical to expand your skills. We must foster good mentoring at the pre-doctoral level to attract students to consider a career in academic dentistry. Once the decision to seek a career as a clinician/scientist has been made, a network of mentors must be established. The Dean or Department Chair may not always be the most appropriate person to serve as mentor, but he or she must work with the new faculty member to make certain that a supportive network is in place.

(7) Develop incentives for post-doctoral experience. The current goal of the Dentist-Scientist Award is to create a clinical specialist with a $\mathrm{PhD}$. The program should be modified so that the goal is to create a clinical specialist with a $\mathrm{PhD}$ and a post-doctoral fellowship. Some would argue that a person can achieve these goals by first completing the Dentist-Scientist Award and a post-doctoral fellowship under the auspices of the National Research Service Award, but the lower salary structure of the NRSA discourages many from pursuing this path. If a training mechanism were created that combined clinical specialty training with a PhD and post-doctoral training, this would underscore the message that the post-doctoral fellowship is absolutely crucial for success. The trainee 
would not need to select the post-doctoral mentor until the last year of the doctoral program. This new training mechanism would enable the student to approach any potential post-doctoral mentor with this attractive offer: "I would like to work with you, and my salary and fringe benefits are already paid in full." It is an offer, as they say in The Godfather, you can't refuse.

(8) Establish a loan repayment program for clinician/scientists. Overwhelming student loan debts, coupled with family obligations, prevent many dental graduates from pursuing careers as clinician/scientists. We live in an era where $93 \%$ of all graduating dental students have some student loan debt (Trends in Dental Education, 1999). In 1999, over $40 \%$ of students who graduate from public dental schools will have student loan debts in excess of $\$ 100,000$; over $40 \%$ who graduate from private dental schools will have student loan debts in excess of $\$ 150,000$ (Trends in Dental Education, 1999). These overwhelming debt burdens dissuade many from even considering a career in academic dentistry. Loan forgiveness programs-programs that pay a portion of the student's educational loans for each year of serviceare effective tools to address manpower shortages. Existing loan repayment programs sponsored by the National Institutes of Health repay as much as $\$ 35,000$ of student loans per year for individuals engaged in research at the NIH in the fields of HIV/AIDS or contraception and infertility. These programs should be expanded to include scientists engaged in dental and craniofacial research at the NIH and at extramural institutions.

\section{A starting point for solutions}

As we write this editorial, there are approximately 200 unfilled faculty positions within the nation's dental schools, with few takers in the pipeline. There are shortages in both the number of people interested in pursuing an academic career and the number of qualified clinicians/scientists to fill the available positions. These shortages represent a significant threat to our profession. Our leaders must take responsibility for dealing with this threat. Too often, our leaders come from either a clinical or scientific culture and do not always appreciate the other. Our leaders must not only appreciate both the science and the art of our profession, they must also take responsibility for drawing the two together in a process that begins with coming together themselves.

\section{Reference}

Trends in Dental Education (1999). The survey of dental school seniors. Washington, DC: American Association of Dental Schools. 